\title{
Counter-Current Chromatography Separation of Isatin Derivatives using the Sandmeyer Methodology
}

\author{
Márcia R. Almeida, ${ }^{*, a}$ Gilda G. Leitão, ${ }^{b}$ Bárbara V. Silva, ${ }^{a}$ Jussara P. Barbosa ${ }^{c}$ and \\ Angelo C. Pinto ${ }^{a}$ \\ ${ }^{a}$ Instituto de Química, Universidade Federal do Rio de Janeiro, Centro de Tecnologia, Bl.A, Ilha do \\ Fundão, 21941-909 Rio de Janeiro-RJ, Brazil \\ ${ }^{b}$ Núcleo de Pesquisas de Produtos Naturais, Centro de Ciências da Saúde, Universidade Federal do \\ Rio de Janeiro, Bl.H, Ilha do Fundão, 21941-590 Rio de Janeiro-RJ, Brazil \\ 'Laboratório de Taxonomia, Bioquímica e Prospecção de Fungos, Fundação Oswaldo Cruz, \\ Instituto Oswaldo Cruz, Manguinhos, 21949-900 Rio de Janeiro-RJ, Brazil
}

\begin{abstract}
Uma metodologia rápida e eficiente foi desenvolvida para separação de isômeros de isatinas utilizando a técnica de cromatografia contracorrente de alta velocidade. Os isômeros de derivados de isatinas foram preparados segundo a metodologia de Sandmeyer e separados com o sistema de solventes hexano:acetato de etila:etanol:água 1:0,5:0,5:1 (v/v/v/v).
\end{abstract}

A rapid and efficient method, using high-speed counter-current chromatography (HSCCC) technique, was developed for the separation of isomeric isatin derivatives, prepared following the Sandmeyer route. The biphasic solvent system composed of hexane:ethyl acetate:ethanol:water 1:0.5:0.5:1 (v/v/v/v) was used for all separations.

Keywords: isatins, Sandmeyer methodology, isomers separation, counter-current chromatography

\section{Introduction}

Isatin $(\mathbf{1}, \mathrm{R}=\mathrm{H})$ is a natural product found in plants of the genus Isatis. ${ }^{1}$ This compound is also found in urine and brain regions associated with hunger, but its endogenous role is not yet fully understood. ${ }^{2}$ Recently, Grougnet et al. ${ }^{3}$ isolated 6-methoxy-1-methylisatin from Boronella koniambiensislies aerial parts. Furthermore isatin and its derivatives are important raw materials for drug synthesis. ${ }^{4-6}$ Thus 5 -fluoroisatin is the precursor of the Sunitinib (Sutent $\left.{ }^{\circledR}\right)$ drug, approved by the Food and Drugs Administration (FDA) in 2006 for treatment of renal cell carcinoma (RCC) and gastrointestinal stromal tumor (GIST). ${ }^{7}$ In addition to antitumor activity these substances exhibit antiviral, anti-inflammatory and anticonvulsant properties. ${ }^{8-11}$

The isatins are generally synthesized in the laboratory and commercially available but are expensive, especially those substituted in the aromatic ring.

\footnotetext{
*e-mail: marcialmeida@iq.ufrj.br
}

Traugott Sandmeyer (1854-1922) was the first to investigate a route for the synthesis of isatins and his methodology, even today, is the most used because of the experimental simplicity, large number of anilines available and large number of isatins obtained. ${ }^{12}$ The Sandmeyer methodology involves treating a substituted aniline (2) with chloral hydrate and hydroxylamine hydrochloride (or other hydroxylamine salt), in an aqueous sodium sulfate medium and subsequent cyclisation of the isonitrosoacetanilide formed (3) in sulphuric acid ${ }^{12,13}$ (Figure 1).

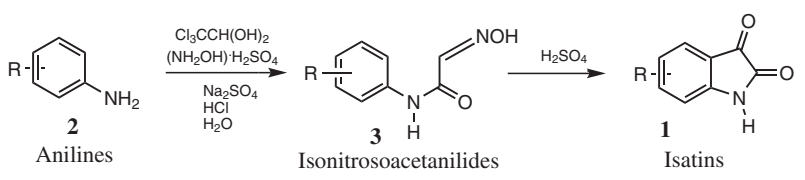

Figure 1. Sandmeyer methodology modified by Marvel and Hiers. ${ }^{13}$

In the case of 3-substituted anilines, the cyclisation step in the Sandmeyer procedure can potentially afford a mixture of two isomers (see pathway a or b in Figure 2). 
In general, the regiochemistry of the product formation is controlled by the use of an atom to block one of two potential cyclisation positions and then subsequent removal of this atom affording either the 4 - or the 6-substituted compounds. ${ }^{14}$ In order to avoid this further step in the synthetic route of 4- and 6-substituted isatins, a key would be to separate off these isomers inevitably formed in the cyclisation step.

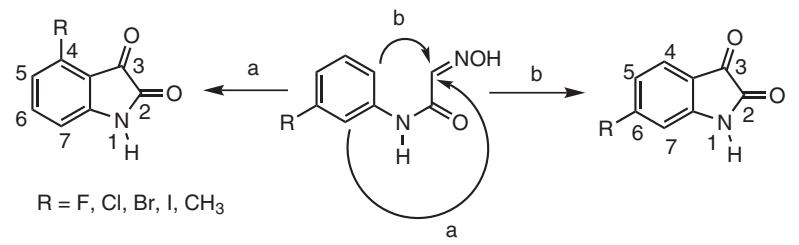

Figure 2. Pathway a: formation of the 4-substituted-isatin; Pathway b: formation of the 6-substituted-isatin.

The 4- and 6-substituted isomers have been reported as intermediates in the synthesis of indirubins, which are potent and selective inhibitors of glycogen synthase kinase-3 and cyclin-dependent kinases. ${ }^{15}$ The same group, in 2005 , patented methods for the treatment of protozoanmediated diseases, Alzheimer's disease and diabetes with 4- and 6-substituted Indirubin-type compounds. ${ }^{16}$

Isatins are also used in the preparation of anthranilates by oxidation with hydrogen peroxide. ${ }^{17}$ Anthranilic acids have a wide application in organic synthesis, especially in the synthesis of polycyclic aromatic hydrocarbons..$^{18-20}$

The development of a simple, fast and economic chromatographic technique for the separation of these isomers is, therefore, of great relevance. The traditional separation of these reaction products on silica gel column chromatography demands a large amount of solvent and time.

This work describes the use of high-speed counter-current chromatography (HSCCC) to separate five pairs of isatin derivative isomers prepared from 3-substituted-anilines: the 4- and 6-fluoro-, chloro-, bromo-, iodo- and methylisatins.

\section{Experimental}

Synthesis

All isatin derivatives were prepared according to Sandmeyer methodology. ${ }^{12,13}$ All compounds were analyzed by GC-MS using a Hewlett Packard (Palo Alto, CA) 6890N GC system and a Hewlett Packard 5973 mass selective detector and were characterized by their standards.

\section{Choice of the solvent system}

Small amounts of the isomers were dissolved in separate test tubes containing the solvent system to be tested. The test tubes were shaken and the compounds allowed to partition between the two phases. After equilibrium each phase was analyzed by thin-layer chromatography (TLC) and gas chromatography-mass spectrometry (GC-MS). The elution system dichloromethane:ethyl acetate $20 \%$ was used for TLC analyses and the compounds were visualized under UV light (254 nm).

\section{GC-MS analysis}

GC-MS analyses were performed on an HP 6890N GC system and a HP 5973 MSD. A non-polar capillary column DB1 (100\% dimethylpolysiloxane phase, $30 \mathrm{~m} \times 0.25 \mathrm{~mm}$ i.d., $0.25 \mu \mathrm{m}$ film thickness; J \& W Scientific, UK) was used for isomers separation from isatin derivatives. The flow rate of the carrier gas (helium) was $0.5 \mathrm{~mL} \mathrm{~min}^{-1}$ and the analyses were performed at constant pressure of 4.84 psi. The samples were injected $(1 \mu \mathrm{L})$ using a split injection (split ratio 1:30.6) at $290^{\circ} \mathrm{C}$. The GC oven was programmed from 150 to $270{ }^{\circ} \mathrm{C}$ ( $5 \mathrm{~min}$ isothermal) at $15^{\circ} \mathrm{C} \mathrm{min}^{-1}$. The total time of analysis was $13 \mathrm{~min}$. Spectra were recorded in the scan mode at $70 \mathrm{eV}$.

The GC-MS analysis conditions for the separation of the methylisatin isomers were different. The GC oven was programmed from 100 to $210{ }^{\circ} \mathrm{C}$ (10 min isothermal) at $12{ }^{\circ} \mathrm{C} \mathrm{min}^{-1}$. The helium flow was $0.6 \mathrm{~mL} \mathrm{~min}^{-1}$. The sample was injected at $260^{\circ} \mathrm{C}$, using a 1:20 split ratio. The total time of analysis was $19.17 \mathrm{~min}$.

\section{HSCCC separations}

Isomers 4- and 6-fluoroisatin, 4- and 6-bromoisatin and 4- and 6-methylisatin were separated on a P.C. Inc. (Potomac, MD, USA) counter-current chromatograph equipped with a multi-layer coil equilibrated by a counterweight. The coil volume was $80 \mathrm{~mL}(1.6 \mathrm{~mm}$ internal diameter) and a Waters model M45 solvent delivery system (Waters, MA, USA). Isomers 4- and 6-chloroisatin and 4- and 6-iodoisatin were separated on a HTPrep Quattro CCC (AECS, Bridgend, UK) counter-current chromatograph equipped with two bobbins containing two multilayer coils each (Bobbin 1: $26 \mathrm{~mL}$ and $240 \mathrm{~mL}$, Bobbin 2: 95 and $98 \mathrm{~mL}$ ). The volume of the coil was $95 \mathrm{~mL}$ (2.0 mm internal diameter). The pump was a model Series II. In both cases a L-7650 Fraction collector (Merck, Germany) was used. All separations were performed at $850 \mathrm{rpm}$; fractions of $4 \mathrm{~mL}$ were collected at a flow rate of $2 \mathrm{~mL} \mathrm{~min}^{-1}$. Fractions were monitored by TLC and GC-MS.

The solvent system hexane:ethyl acetate:ethanol:water 1:0.5:0.5:1 ( $\mathrm{v} / \mathrm{v} / \mathrm{v} / \mathrm{v})$ was used for all isomer separations. The stationary lower phase of the solvent system was pumped 
into the coil in the tail-to-head direction. After the coil was filled with stationary phase, rotation started and the mobile phase was pumped until all the excess of stationary phase came out of the coil. The retention of stationary phase $\left(\mathrm{S}_{\mathrm{F}}\right)$ for the separations performed at the P.C. Inc apparatus was approximately $80 \%\left(\mathrm{~V}_{\mathrm{S}}=64 \mathrm{~mL}, \mathrm{~V}_{\mathrm{M}}=16 \mathrm{~mL}\right)$ and for those performed at the HTPrep $\mathrm{S}_{\mathrm{F}}$ was approximately $84 \%$ $\left(\mathrm{V}_{\mathrm{S}}=67 \mathrm{~mL}, \mathrm{~V}_{\mathrm{M}}=13 \mathrm{~mL}\right)$. All mixtures containing 4- and 6-substituted isatins were dissolved in $2.5 \mathrm{~mL}$ of the upper phase and $2.5 \mathrm{~mL}$ of the lower phase of the biphasic solvent system hexane:ethyl acetate:ethanol:water 1:0.5:0.5:1 $(\mathrm{v} / \mathrm{v} / \mathrm{v} / \mathrm{v})$ and injected in the coil. $K_{D}$ were estimated by TLC of the collected fractions where approximately equal aliquots of each fraction were spotted on the TLC plate.

\section{Separation of 4- and 6-fluoroisatin}

The mixture of 4- and 6-fluoroisatins (89 mg) was dissolved in $5.0 \mathrm{~mL}$ of the solvent system and applied in the $80 \mathrm{~mL}$ coil of the P.C. Inc equipment. Sixty fractions were collected $(4.0 \mathrm{~mL}$ each) and the rotation was stopped on tube 41 . The fractions were analyzed by TLC and GC-MS. The GC-MS analysis showed 4-fluoroand 6-fluoroisatin with 5.9 and 5.4 min retention times, respectively. 4-Fluoroisatin was obtained in a pure form in tubes 34-43 (2 mg, $K_{D}$ approx. 2.0) and 6-fluoroisatin was obtained in a pure form in tubes 19-33 (24 mg, $K_{D}$ approx. 1.6 , yielding $27 \%$ ).

\section{Separation of 4- and 6-chloroisatin}

The sample containing 4- and 6-chloroisatins (47 mg) was dissolved in $5.0 \mathrm{~mL}$ of the solvent system and applied in the $95 \mathrm{~mL}$ coil of the HTPrep equipment. Eighty four fractions were collected $(4.0 \mathrm{~mL}$ each) and rotation was stopped on tube 69 . The fractions were analyzed by TLC and GC-MS. The GC-MS analysis showed 4- and 6-chloroisatin with 7.3 and $6.8 \mathrm{~min}$ retention times, respectively. 4-Chloroisatin was obtained in a pure form in tubes 33-60 (20 mg, $K_{D}$ approx. 1.9, yielding 42\%) and 6-chloroisatin was obtained in a pure form in tubes 17-27 (15 mg, $K_{D}$ approx. 0.9, yielding $32 \%$ ).

\section{Separation of 4- and 6-bromoisatin}

The mixture of 4- and 6-bromoisatins (43 mg) was dissolved in $5.0 \mathrm{~mL}$ of the solvent system and applied in the $80 \mathrm{~mL}$ coil of the P.C. Inc equipment. Seventy fractions were collected $(4.0 \mathrm{~mL}$ each) and rotation was stopped on tube 40 . The fractions were analyzed by TLC and GC-MS. The GC-MS analysis showed 4- and 6-bromoisatin with
8.0 and $7.5 \mathrm{~min}$ retention times, respectively. 4-Bromoisatin was obtained in a pure form in tubes $21-38$ (15 mg, $K_{D}$ approx. 1.4, yielding 35\%) and 6-bromoisatin was obtained in tubes 6-19 (18 mg, $K_{D}$ approx. 0.5, yielding 42\%).

\section{Separation of 4- and 6-iodoisatin}

The sample containing 4- and 6-iodoisatins (40 mg) was dissolved in $5.0 \mathrm{~mL}$ and applied in the $95 \mathrm{~mL}$ coil of a HTPrep equipment. Eighty four fractions were collected (4.0 mL each) and rotation was stopped on tube 69. The fractions were analyzed by TLC and GC-MS. The GC-MS analysis showed 4- and 6-iodoisatin with 8.9 and 8.4 min retention times, respectively. The 4-iodoisatin was obtained in a pure form in tubes $19-26$ (18 $\mathrm{mg}, K_{D}$ approx. 1.0, yielding $45 \%$ ) and 6-iodoisatin was obtained in a pure form in tubes $12-15$ (7 mg, $K_{D}$ approx. 0.6, yielding 17\%).

\section{Separation of 4- and 6-methylisatin}

The mixture of 4- and 6-methylisatins $(65 \mathrm{mg})$ was dissolved in $5.0 \mathrm{~mL}$ of solvent system and applied in the $80 \mathrm{~mL}$ coil of the P.C. Inc equipment. Seventy fractions were collected (4.0 mL each) and rotation was stopped on tube 50 . The fractions were analyzed by TLC and GC-MS. The GC-MS analysis showed 4- and 6-methylisatin with 10.8 and 11.2 min retention times, respectively. The 4-methylisatin was obtained in a pure form in tubes 15-20 (23 mg, $K_{D}$ approx. 0.9, yielding 35\%) and 6-methylisatin was obtained in a pure form in tubes $36-41$ (22 $\mathrm{mg}, K_{D}$ approx. 1.9, yielding 34\%).

\section{Results and Discussion}

This paper describes the investigation of the separation of a series of isomeric isatins bearing electron donating and electron withdrawing groups by HSCCC. Hence a series of 3-halogen ( $\mathrm{F}, \mathrm{Cl}, \mathrm{Br}$ and $\mathrm{I})$ and 3-methylisonitrosoacetanilides were prepared following the Sandmeyer route.

The cyclisation of these isonitrosoacetanilides resulted in isomeric mixtures of 4- and 6-substituted isatins in varying proportions. The 4- and 6-chloro and bromo derivatives were formed in almost the same proportion (Figure 3), suggesting that the electronic density in the C-2 and C- 6 carbons of the isonitrosoacetalidines (Figure 2) are similar. The cyclisation of the 3 -fluoro-isonitrosoacetanilide was regioselective for the formation of the 6-fluoroisatin. The ortho inductive effect of the fluorine atom can explain the low proportion of 4-fluoroisatin. The cyclisation of 3-iodo-isonitrosoacetanilide favored formation of the 
4-iodoisatin. The iodo atom, due to its size, increases the electron density on C-2 carbon. These results are in agreement with the work done by Sadler in $1955 .{ }^{21}$

The nitro and methoxyl groups, that are classically studied when substituent effects are evaluated, were not included in this study since 3-nitro isonitrosacetanilide does not yield the respective isatins and the 3-methoxyisonitrosoacetanilide gives the 6-methoxyisatin selectively. ${ }^{21}$ Traditionally these reaction products are separated by silica gel column chromatography, but this technique demands a large amount of solvent and time. Other less efficient method involves precipitation with hydrochloric and acetic acids. ${ }^{21}$ Therefore HSCCC was used as an alternative and cheaper method than both. As this technique uses no solid support, samples can be completely recovered.

The solvent system used in all separations was composed of hexane:ethyl acetate:ethanol:water 1:0.5:0.5:1 $(\mathrm{v} / \mathrm{v} / \mathrm{v} / \mathrm{v})$; the resulting organic phase was the mobile phase. The elution order of the 4- and 6-isomers, at HSCCC separations, as predicted by $K_{D}$ calculations, is the same as that for GC analyses (Table 1). In the two chromatographic techniques the 6-substituted isatin derivatives have lower retention times, and so they were the first ones to be eluted, followed by the 4-substituted isatins, except in the
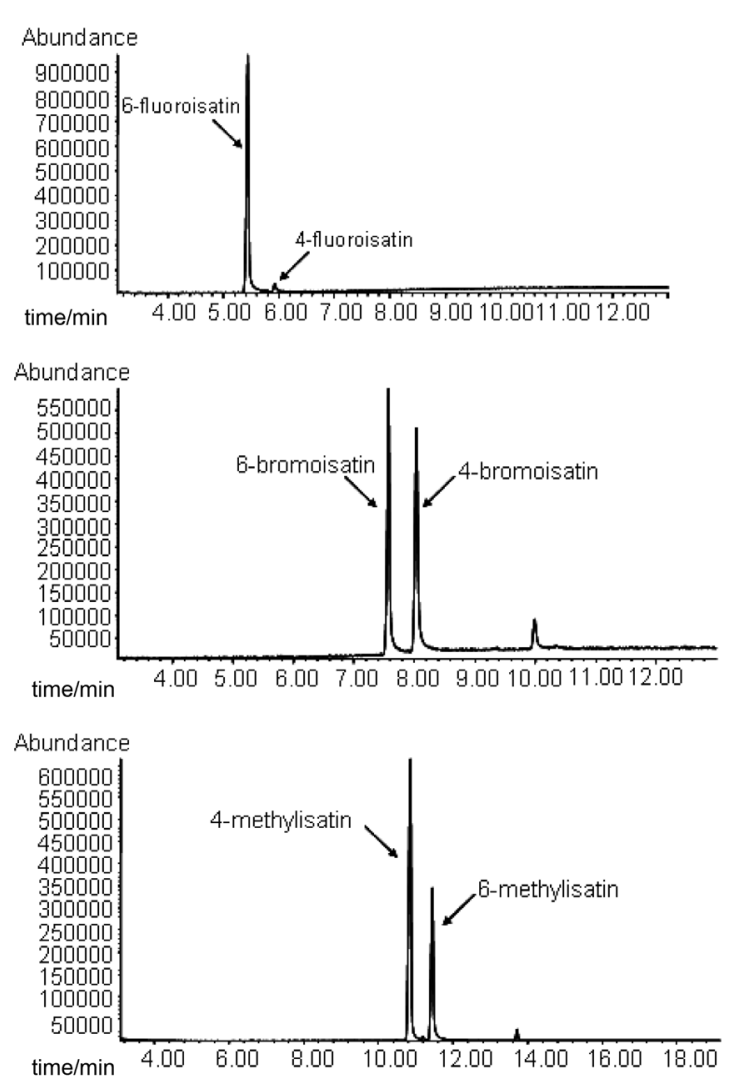

case of methylisatin isomers. The electronic effects of the halogen substituting groups, allied to their volume make the 6-substituted-isatins less polar, decreasing retention time in respect to the 4-substituted-isatins. This fact is not true for the methyl derivatives. This is clearly shown when we compare the values of $K_{D}$ for the chloro derivatives and the methyl derivatives, which are 1.9 for the 4-chloroisatin

Table 1. Elution order for the isatin isomers, retention time for GC-MS analyses, $K_{D}^{*}$ and yielding for separation

\begin{tabular}{lccc}
\hline Isomer of Isatin & $\begin{array}{c}\text { Retention time (min) } \\
\text { for GC-MS analyses }\end{array}$ & $K_{D}$ & $\begin{array}{c}\text { Yielding } \\
(\%)\end{array}$ \\
\hline 4-Fluoroisatin & 5.9 & 2.0 & - \\
6-Fluoroisatin & 5.4 & 1.6 & 27 \\
4-Chloroisatin & 7.3 & 1.9 & 42 \\
6-Chloroisatin & 6.8 & 0.9 & 32 \\
4-Bromoisatin & 8.0 & 1.4 & 35 \\
6-Bromoisatin & 7.5 & 0.5 & 42 \\
4-Iodoisatin & 8.9 & 1.0 & 45 \\
6-Iodoisatin & 8.4 & 0.6 & 17 \\
4-Methylisatin & 10.8 & 0.9 & 35 \\
6-Methylisatin & 11.2 & 1.9 & 34 \\
\hline
\end{tabular}

$* K_{D}$ values were estimated by TLC monitoring of the eluted fractions.

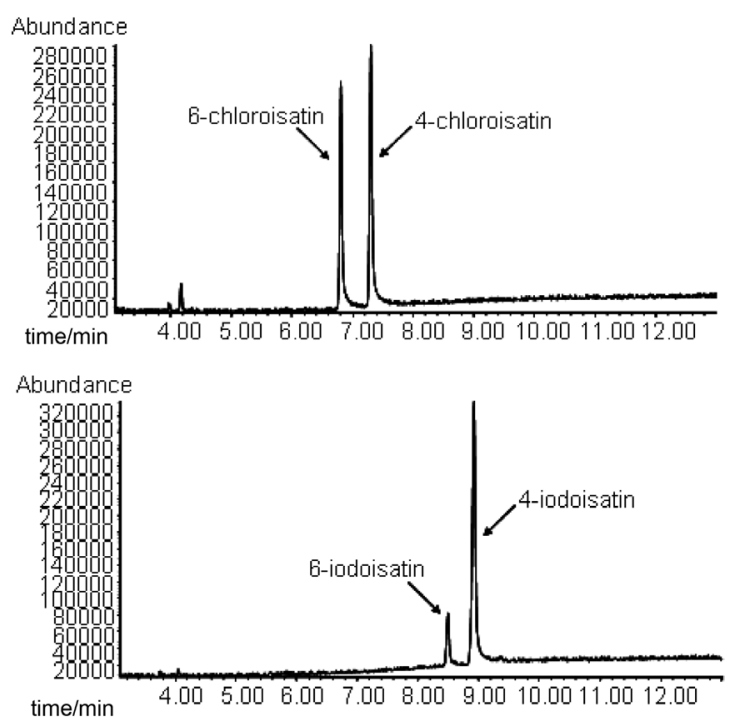

Figure 3. GC-MS chromatograms of the isomers from isatin derivatives before HSCCC separation. For conditions, see Experimental section. 

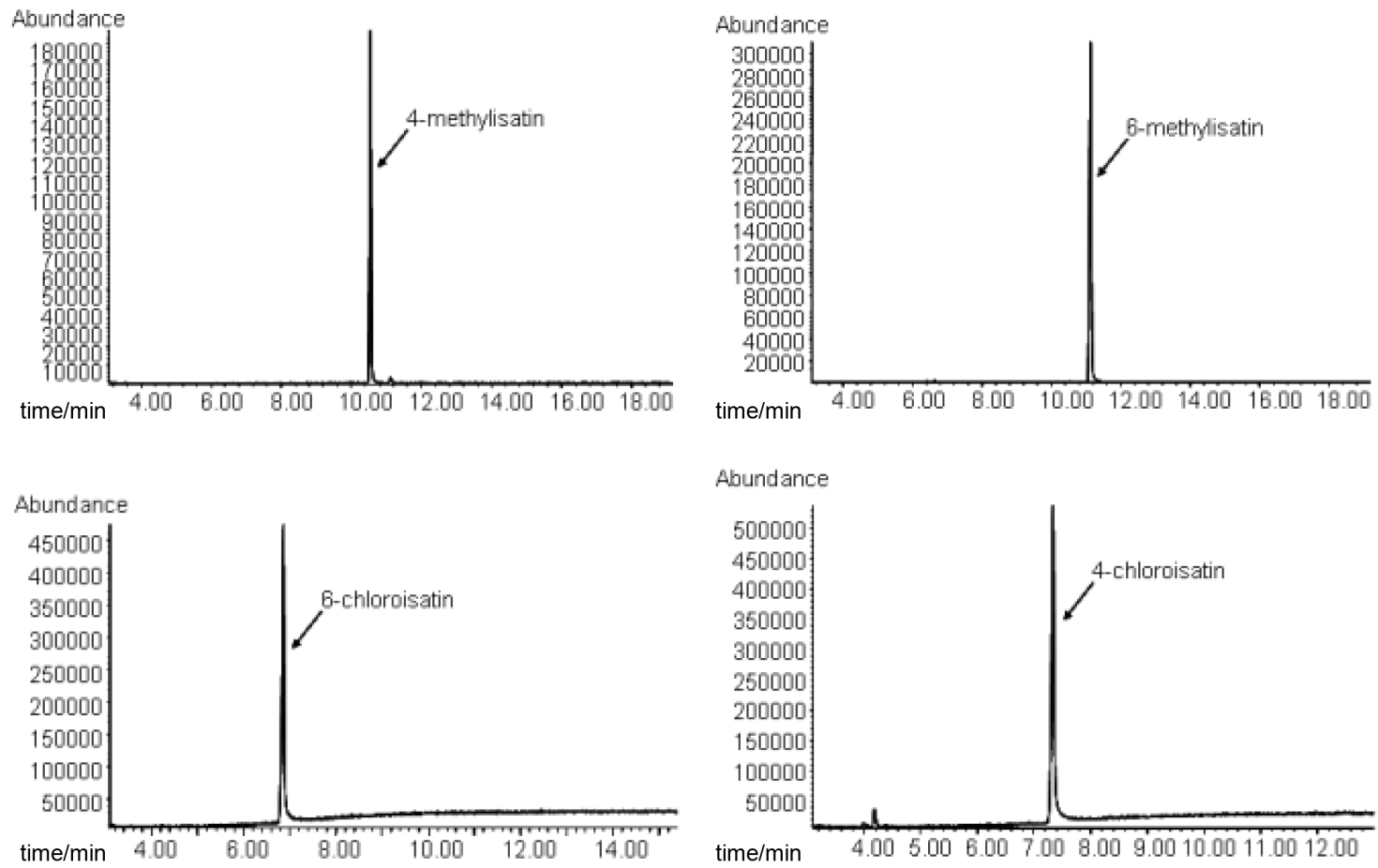

Figure 4. GC-MS chromatograms of the 4 and 6-methylisatin and 4 and 6-chloroisatin isomers after HSCCC separation. For conditions, see Experimental section.

and for 6-methylisatin and 0.9 for 6-chloroisatin and for 4-mehtylisatin. It is also interesting to note that more electronegative halogens render isatin derivatives more polar, as can be seen by the decrease in $K_{D}$ values shown in Table 1.

All separated 4- and 6-substituted isomers were identified by GC-MS analyses. Some GC chromatograms are shown in Figure 4.

It was possible to show by this study that the method is repeatable, since the work used different CCC equipments bearing coils with different internal diameters for the isomer separations. The slightly different retentions of stationary phase for the same solvent system, obtained from the two equipments, can be due to the different internal diameter of the two coils $(1.6 \mathrm{~mm}$ for the PC Inc. coil and $2.0 \mathrm{~mm}$ for the Quattro coil used)

\section{Conclusions}

HSCCC proved to be an efficient technique for the separation of isomers from isatin derivatives obtained from the Sandmeyer's methodology. The advantage of this technique is the use of the same solvent system to separate different substituted isatins. In addition, shorter elution times and lower solvent volume are required for the separation when compared to conventional liquid chromatography technique.

\section{Acknowledgments}

Authors are grateful to the financial support from Brazilian agencies CNPq and FAPERJ.

\section{References}

1. Guo, Y.; Chen, F.; Zhongcaoyao 1986, 17, 104.

2. Tozawa, Y.; Ueki, A.; Manabe, S.; Matsushima, K.; Biochem. Pharmacol. 1998, 56, 1041; Glover, V.; Bhattacharya, S.K.; Chakrabarti, A.; Sandler, M.; Stress Med. 1998, 14, 225.

3. Grougnet, R.; Magiatis, P.; Fokialakis, N.; Mitaku, S.; Skaltsounis, A.-L.; Tillequin, F.; Sévenet, T.; Litaudon, M.; J. Nat. Prod. 2005, 68, 1083.

4. Da Silva, J. M.; Garden, S. J.; Pinto, A. C.; J. Braz. Chem. Soc. 2001, 12, 273.

5. Garden, S. J.; Torres, J. C.; Ferreira, A. A.; Silva, R. B.; Pinto, A. C.; Tetrahedron Lett. 1997, 38, 1501.

6. Silva, R. B.; Torres, J. C.; Garden, S. J.; Violante, F. A.; Rezende, M. J. C; Silva, B. V.; Pinto, A. C.; Quim. Nova. 2008, 31, 924.

7. Roskoko Jr, R.; Biochem. Biophys. Res. Commun. 2007, 356, 323; Sun, S.; Schiller, J. H.; Crit. Rev. Oncol. Hematol. 2007, 62, 93.

8. Zhou, L.; Liu, Y.; Zhang, W.; Wei, P.; Huang, C.; Pei, J.; Yuan, Y.; Lai, L.; J. Med. Chem. 2006, 49, 3440.

9. Matheus, M. E.; Violante, F. A.; Garden, S. J.; Pinto, A. C.; Fernandes, P. D.; Eur. J. Pharmacol. 2007, 556, 200. 
10. Yogeeswari, P.; Sriram, D.; Thirumurugan, R.; Raghavendran, J. V.; Sudhan, K.; Pavana, R. K.; Stables, J.; J. Med. Chem. 2005, 48, 6202.

11. Vine, K. L.; Locke, J. M.; Ranson, M.; Pyne, S. G.; Bremner, J. B.; J. Med. Chem. 2007, 50, 5109.

12. Sandmeyer, T.; Helv. Chim. Acta 1919, 2, 234.

13. Marvel, C. S.; Hiers, G. S.; Org. Synth. Coll. 1941, 1, 327.

14. Uddin, M. K.; Reignier, S. G.; Coulter, T.; Montalbetti, C.; Grånäs, C.; Butcher, S.; Krog-Jensen, C.; Felding, J.; Bioorg. Med. Chem. Lett. 2007, 17, 2854.

15. Polychronopoulos, P.; Magiatis, P.; Skaltsounis, A. L.; Myrianthopoulos, V.; Mikros, E.; Tarricone, A.; Musacchio, A.; Roe, S. M.; Pearl, L.; Leost, M.; Greengard, P.; Meijer, L.; J. Med. Chem. 2004, 47, 935.
16. Meijer, L.; Greengard, P.; Knockaert, M.; Skaltounis, A. L.; US Pat. 605155712003.

17. Prinz, W.; Kayle, A.; Levy, P. R.; J. Chem. Res. (S), 1978, 116.

18. Wilcox Jr., C. F.; Farley, E. N.; J. Am. Chem. Soc. 1984, 106, 7195 .

19. Newman, M. S.; Kannan, R.; J. Org. Chem. 1976, 41, 3356.

20. Baker, B. R.; Schaub, R. E.; Joseph, J. P.; McEvoy F. J.; Williams, J. H.; J. Org. Chem. 1952, 17, 164.

21. Sadler, P. W.; J. Org. Chem. 1956, 21, 169.

Received: March 26, 2009

Web Release Date: December 30, 2009 